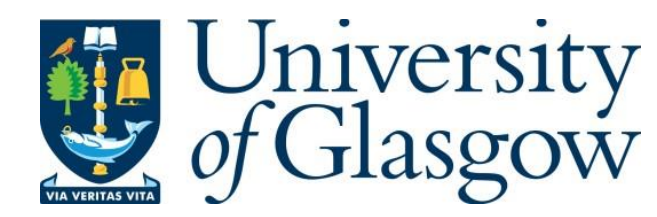

Barker, T. (2019) Cultural techniques of play: a media philosophical approach to the study of time, history and memory in games. Configurations, 27(1), pp. 87-110. (doi:10.1353/con.2019.0003)

There may be differences between this version and the published version. You are advised to consult the publisher's version if you wish to cite from it.

http://eprints.gla.ac.uk/171310/

Deposited on: 12 October 2018

Enlighten - Research publications by members of the University of Glasgow http://eprints.gla.ac.uk 


\section{Cultural Techniques of Play: A media philosophical approach to the study of time, history and memory}

in games

\section{Abstract}

Taking Johan Huizinga's work on games and culture as a starting point - particularly his arguments about how play can be considered as primary to culture - this paper gives a new account of $21^{\text {st }}$ century play as kulturtechniken (cultural technique). Using examples including the art games and indie games That Dragon, Cancer (Numinous Games, 2016), The Outlands (Haines and Hinterding, 2011), and Superhot (Superhot Team 206), the paper explores the way time is ordered in gaming and develops a media theoretical approach to explain the way play might 'cultivate' a certain way of living in and thinking about the world, particularly through its time-critical operation. The three examples are chosen because in each of them we can see a different element of digital temporality, including: the way time is ordered by computational systems; the way memories and histories are archived and made discoverable by digital systems; and the way interface design can facilitate experiences of being-in-time. By exploring gaming as a cultural technique, the paper enters into a field of debate in media and cultural studies that addresses the concepts of contemporaneity and digital temporality and offers a new way to approach these areas of study through a focus on games.

Keywords: Game studies; media philosophy; games and time; media and time; cultural technique.

Cultural techniques of Play: A media philosophical approach to the study of time, history and memory in games

Play begins, and then at a certain moment it is 'over'. It plays itself to an end. While in process all is movement, change, alternation, succession, association, separation. But immediately connected with its limitation as to time there is a further curious feature of play: it at once assumes fixed form as a cultural phenomenon. Once played, it endures as a new-found creation of the mind, a treasure to be retained by the memory. It is transmitted, it becomes tradition.

Johan Huizinga, Homo Ludens: The Play Element in Culture, 1949, 9-10

After Johan Huizinga's Homo Ludens, cultural history and theory could begin to explain the development of social traditions as deeply indebted to a foundational act of play. Play, as Huizinga points out, is time-bound: It begins and ends. But, curiously, it also becomes fixed as a cultural phenomenon, like a ritual or a routine that is repeated and endures. Following Huizinga's original observations, in this paper I explore the way that the 
structures and conditions for play in the $21^{\text {st }}$ century can be considered as giving character to contemporary culture, particularly concerning the representability of time. In order to do this, I argue that play should be rethought as what media theorists in the German tradition - notably Thomas Macho, Bernhard Siegert, and Sybille Krämer - have described as kulturtechniken (cultural technique); that is, as a repeated practice that 'cultivates' a certain way of living in and thinking about the world. The paper links the work of Huizinga to German media theory by describing play as a cultural technique, which allows me in what follows to explore the way time works in video games - both in terms of its representation and its operation - and the way that this supports the social traditions that have come to characterise so-called digital culture. The paper is media philosophical in its method, using an analysis of the operation of contemporary digital media to address philosophical concepts of time and society. As such, it offers a way of approaching the study of time and games from a new angle, turning away from hermeneutics and towards an approach that focusses on media conditions. The hypothesis that frames this argument, following Huizinga, is that play can not only offer players new senses of time, but that it also has started to become characteristic of the temporal dissonances of the contemporary, with play now becoming one of the characteristics of digital culture in general.

The time produced by contemporary media systems has been variously described as discontinuous, ${ }^{1}$ multiple ${ }^{2}$ and often conflicting. ${ }^{3}$ Theorists including Boris Groys, ${ }^{4}$ Wolfgang Ernst, ${ }^{5}$ Terry Smith $^{6}$ and Sarah Sharma ${ }^{7}$ have, in very different ways, focussed on experiences of temporality to describe the conditions for experience in so-called 'global' culture, with its complex of different types of time. Through the analysis of both media systems and art systems, they have all begun to explore the multiple variations of time and the radically different historical narratives that co-exist within the so-called global. What has been missing however is a focus on games as a media system that adds significantly to the way that time can be represented and the way that media might support varying conditions of being-in-time. The paper looks to further inform the discourse around

\footnotetext{
${ }^{1}$ Wolfgang Ernst, Chronopoetics: The Temporal Being and Operativity of Technological Media. (Lanham: Rowman and Littlefield, [2012]2016), pp 63-65.

2 Timothy Barker, Time and the Digital: Connecting Aesthetics, Technology and a Process Philosophy of Time. (New Hampshire: Dartmouth College Press, 2012), pp. 162-167.

${ }^{3}$ Terry Smith, "Introduction: The Contemporary Question" in Antomonies of Art and Culture. Terry Smith, Okwui Enwezor, and Nancy Condee (eds.) (Durham and London: Duke University Press, 2008), pp. 6-11.

${ }^{4}$ Boris Groys, In the Flow. (London and New York: Verso, 2016).

${ }^{5}$ Wolfgang Ernst, Chronopoetics: The Temporal Being and Operativity of Technical Media (London and New York: Rowman and Littlefield, 2016)

${ }^{6}$ Terry Smith, What is Contemporary Art (Chicago: The University of Chicago Press, 2009)

${ }^{7}$ Sarah Sharma, In the Meantime: Temporality and Cultural Politics (Durham and London: Duke University Press).
} 
contemporaneity, which involves philosophers, cultural theorists and art historians, and which seeks to address the characteristics of time and temporal experience in the current historical moment. In order to explore the way time and the contemporary has been given form in play, I use examples from the art games and indie games, The Outlands (Haines and Hinterding 2011), That Dragon, Cancer (Numinous Games 2016) and Superhot (Superhot Team 2016), each of which focus on a different aspect of contemporaneity and each of which amplify and offer a way to analyse the common gaming tropes associated with the temporality of mainstream video games.

\section{Games as refrain}

Games not only provide images that, like cinema or television, represent time-based events - a representation of the historical world; the image on the screen; the make-believe image of child's play; the image conjured by, for example, Dungeons and Dragons - but, in a way that is unique, they also express the time-based and timecritical operation of their programs. Whether in video games, board games or children's make-believe, the player of a game always interacts with a machine that not only provides them with images but also with conditions for action. The machine of the game defines the players from its own perspective so that play can function. This machine may take the form of a computer, or the rules, conditions and limits of non-digital games, which, in a wholly Deleuze and Guattarian manner, interrupts at every moment of playfulness and sets the conditions that direct the flow(s) of play. In a playground game of tag, the game defines who is 'in' and who is not, based on the rule of who was touched last. The game of chess sets specific limits on movement.

Likewise, in digitally mediated games, the player is defined as a computer readable input, that is used to trigger action. As Deleuze and Guattari write, when anything or anyone escapes and creates they are never alone, but rather passing through an 'abstract machine that produces continuums of intensity, effects conjunctions of deterritorializations, and extracts expressions and contents. ${ }^{8}$ The abstract machine of the game, as that thing which sweeps playfulness along, thus provides a 'state space', to use the media technical language, in which multiple possibilities for experience are embedded. The game, its rules, and the tendencies it supports, are the abstract components of the articulation of the real achieved through play. ${ }^{9}$ They condition the movement of toand-fro, move and counter move, that is characteristic of play. As an exemplar of Deleuze and Guattari's

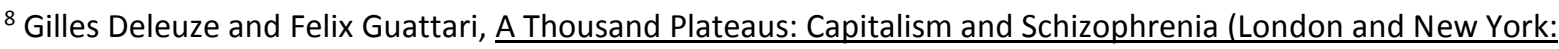
Continuum, [1980]1987), p. 157.

${ }^{9}$ Gilles Deleuze, Felix Guattari and Charles Stivale (1984). Concrete Rules and Abstract Machines. SubStance, 13:3/4 (1984): 7-19, pp. 14-18.
} 
abstract machine, the game simultaneously acts as an interruption and a mode of organisation. It 'constructs a real that is yet to come', ${ }^{10}$ via its function as a machine that conditions the potential that is open to the player.

The game as a refrain, as a machine that interrupts and orders the conditions for experience, can be seen in the way that play is often used as a ritual to structure moments of the day. As Miguel Sicart writes, 'For a long time my day has been structured around play. Lego bricks and toy cars precede my breakfast, as Drop7 and SpellTower lull me to sleep; Noby Noby Boy helps me wait by the printer, and Desert Bus accompanies me in academic meetings. My life takes place in the time between play. ${ }^{11}$ For those of us like Sicart, play serves not only as a distraction or a pass-time but as a refrain, a repeated interruption and sometimes delay of the chronology of moments of day-to-day life.

There is something special about play, however. It is different to the types of rituals previously associated with other media, such as the television and cinema. The game as a refrain is, of course, constituted by the way that it is played. The refrain of play is constituted by the abstract machine of the game. And in its playing the game produces a temporality that is unique. While the cinematic or television apparatus sets up specific conditions for the spectator, such as sitting still in the cinema, looking at the screen, or supporting domestic routines associated with television viewing in the home, it is only in games where the player's input in the media system is 'read' by the text itself, rather than the other way around. Instead of the viewer 'reading' the text, the text 'reads' the viewer and their capacities are defined by the way they are read by the text. From the perspective of theories of digital culture, it is only in the study of games that the importance of the way the media system interprets the user (as input), becomes so highly visible. To play a game, individuals become part of the mechanics of play, as they enter into a time-based system where they make a move, which triggers a response, to which they make a counter-move. ${ }^{12}$

Jesper Juul writes that the happening of play is always 'in the present', which invests a basic sense of 'now' in all games. Christopher Hanson has gone on to suggest that 'whether the game constantly emphasises speedy

\footnotetext{
${ }^{10}$ Deleuze and Guattari, A Thousand Plateaus (above, n. 16), 157.

${ }^{11}$ Miguel Sicart, Play Matters (Cambridge, MA: The MIT Press).p. 6.

12 This type of mediation of temporality has been previously described in terms of game design and textual analysis in Mark J. P. Wolf, "Time in the Video Game," in The Medium of the Video Game, Mark J. P. Wolf ed. (Austin, Texas: University of Texas Press, 2001), pp. 77-91; Jesper Juul, Half-Real: Video Games between Real Rules and Fictional Games (Cambridge, MA: The MIT Press, 2005), pp. 142-155 and Christopher Hanson, Game Time: Understanding Temporality in Video Games (Bloomington: Indiana University Press, 2018).
} 
reactions in real time (as in the case of an action game or sports game) or if it instead slows time to a turn-based structure (as in a strategy game such as Chess) the significance of the player's action at the moment of play is linked to the "now". 13 This rhythm of the to-and-fro, the focus on the present and a relationship to ritual is what has begun to characterise the time of play as a time of the refrain, which is repeated, archived and provides the conditions for action. This is a type of time that is unique to games and it is a type of time, as will be argued in what follows, that has begun to give a character to so-called digital culture that differentiates it from the tradition of Western modernity.

\section{Time-critical cultural techniques}

If cinema, through its photo-mechanical operation of capture and projection, once organised the contingent and made it into history, ${ }^{14}$ the program of games focuses attention back on the contingent as a condition from which information emerges in the present. This may signal a change in the representability of time that mirrors the passage from the historical time of Western modernity to the intensity of different times that constitute the contemporary moment. Instead of a film that moves through the projector and the images that moved past the viewers' eyes one frame at a time, the experience of the contemporary era, being-in-the present - a condition which Boris Groys describes as marked by delays, hesitation, deferral and repetition - might be properly given form by or in play, which is repeated, stored up, and made multiple based on calculations and re-calculations of action. It is not the contingent described by Doane in her analysis of $20^{\text {th }}$ Century media that games capture and make representable. Rather games filter all interaction within the context of play through a system. They do not compose events into a historical narrative, but instead present programs for exploration. In $21^{\text {st }}$ Century media culture, time-based experience becomes able to be understood through the cybernetic systems of games as an outcome of unpredictable inputs at various states. It is the uncertainty of play that game design privileges. ${ }^{15}$ Games invite rather than repress the contingent; they invite playfulness, and they use this as a way to produce new outcomes from their programs.

\footnotetext{
${ }^{13}$ Christopher Hanson, "Repetition" in Routledge Companion to Video Game Studies, ed. Mark J.P. Wolf and Bernard Perron (New York and Oxon: Routledge, 2014), p. 205

${ }^{14}$ See for instance, Jonathan Crary, Techniques of the Observer: On Vision and Modernity in the Nineteenth Century (Cambridge, MA: The MIT Press, 1992) and Mary Ann Doane, The Emergence of Cinematic Time ((Cambridge, MA: Harvard University Press, 2002).

${ }^{15}$ Greg Costikyan, Uncertaintity in Games (Cambridge, MA: The MIT Press, 2015).
} 
As argued above, through both the operation of technology and the experiences of playing with this technology, the video game system keeps attention focussed on the contemporary, on the 'now'. On a purely technical level, every video game is a state machine that changes based on player input. With each change of state, the player makes another input. The system is predicated on the notion of changing its state based on input in the present 'read' against its memory of events. In the media technical sense, computer games focus attention on being-inthe-present because of their operation as state machines and it is through this emphasis on contemporariness that users are able to play games. The game system works as a 'difference that makes a difference' is detected by the game's software, which triggers an output. The contingent here is invited as a condition for game play, as an opportunity to see what else the program can do, since the player's ambition when playing a game is to try and test the limits of play, to experiment with new moves that may achieve new outcomes in the context of the design of the game.

\section{Multiple times of play: The Outlands}

An example might help at this point to illustrate the various experiences of temporality - and the associated ways of thinking of digital subjectivity - available through play. David Haines and Joyce Hinterding's The Outlands (2011) (fig. 1) is an art-game that offers players a chance to experience the time produced by software programs and the limits of the game's interaction design. The Outlands takes the form of an art gallery installation and tests the definition of what a game could be and indeed what might differentiate this genre from digital media art.

In The Outlands there is seemingly not much to do. The game is based on chance events, on a certain contingency of player and game system, rather than any type of goal or endpoint. Within the context of not having much to do, the player is asked to explore, to test the limits of what can and cannot be done in the game. The art-game was built using the Unreal engine and, based on the engine's landscape system, offers players the chance to navigate around an open world made up of four levels, resembling the familiar types of environment encountered in a First-Person Shooter, but without the violence or the stress and without the player being directed through a linear story by tasks or objectives. All the weapons are removed. All human figures are removed. What the player is left with is simply the landscape and the portals between levels, navigated through using the interface of two small tree branches in the art gallery installation. 
The Outlands is an artwork that takes the form of a game in order to offer alternative experiences of play than that which was available in the mainstream games of the 2000s. Since then, the experience of free wandering in a game space has become more popular in game design, seen in sandbox games and the emerging genre of 'walk em ups', and the use of time as a game mechanic has become more central to the experience of digitally mediated play. As an art-game that experiments with the temporality of play at a moment when this was starting to become a key concern for many game designers, it is a good example to illustrate a discussion of time and play.

The nature images and the 'twig interface' of The Outlands are ways that the player/viewer is asked to connect with a deeper sense of time. As play begins it prompts a sense of 'being-in-the-present'; the player must navigate the digital landscape in the here and now. But the experience of drifting through the landscape combined with the texture of the controller, the feeling of the sticks, fragile in your hand, is an artistic device which suggests to the player that they are in touch with much longer durations. ${ }^{16}$ For example, in the installation overly aggressive movements cause the sticks to break, preventing this type of interaction, and the twigs' fragility requires the player to use slower, more controlled movements. The installation is paradoxically about using digital gaming to put players in contact with natural, slower rhythms. Playing this art game, there is an opportunity to experience both what is usually considered 'contemporary' media - that is the up-to-date, and the digital - yet also to encounter a different type of time, one that is folded into the game and unfolded through the

${ }^{16}$ Justin Paton, “Artists, David Haines and Joyce Hinterding on their work 'The Outlands'” Unguided Tours (Art Gallery of New South Wales, 2011) available at https://www.youtube.com/watch?v=YdstMcTGijE 
contingencies of play; where the present involves 'drifting' through the expansive times and spaces of the game.

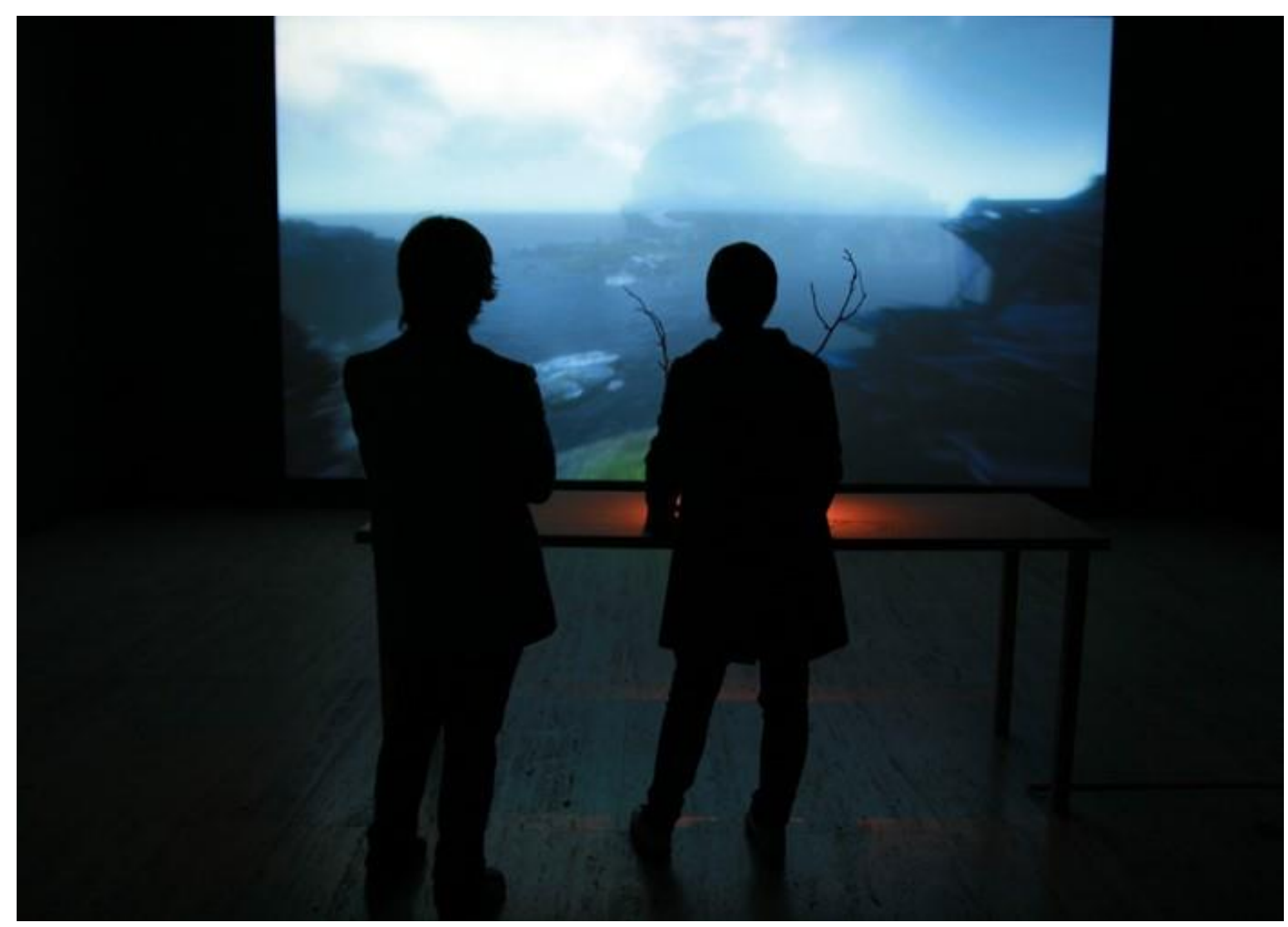

FIGURE 1

Still form David Haines and Joyce Hinterding, The Outlands, 2011

The Outlands, in its emphasis on slowness and drifting, is similar to more well-known games such as Journey (thatgamecompany, 2012). Like The Outlands, Journey presents the player with the conditions to navigate a simulated desert landscape, exploring ruins, activating mythical symbols and co-operating with other players met through the game via its quite limited possibilities for interaction. Unlike The Outlands, however, in Journey there is seemingly an end goal, revealed through the game's cut scenes: The player's journey is directed towards the mountain crevice. It is not until the player reaches the crevice, however, that this end-point is revealed to ultimately loop back to the beginning of the game. Like The Outlands, Journey, through its restricted gameplay and devices such as its musical score and the omission of spoken or written words, as well as its repeated, looping elements, revealed at the game's conclusion, puts player in touch with slower rhythms. 
In both art games the player via, what Rachel Wagner calls the 'ordering making activity' of the game, is asked to engage with a controlled sense of time. ${ }^{17}$ In The Outlands more so than Journey, this is made overt and actually constitutes one of the main features of the art game. The Outlands not only allows users to interact over long durations, exploring without direction or objectives, but also, because of the fragile interface that only allows slow and gentle movements reminds users that they are experiencing a controlled sense of time. The experience of the contemporary provided by Haines and Hinterding is one where the game is used to put players in contact with new senses of time, but only through the affordances provided by the cybernetic system of the game. This game is a particularly good example to use to begin to see the way contemporaneity can be expressed both in art and games because of the way it focusses attention both on the present of interaction, on the contingent, and the way media systems organise this present as well as other exterior or intuitive perceptions of historical or extended time. In the following section, we can now go deeper into the critical discourse around contemporaneity and what is offered by using this approach to conceptualise time and playfulness.

\section{What is contemporaneity?}

The term 'contemporaneity' is now commonly used to describe the historical present and is designed to capture an intense depth of temporal difference. As a replacement for the conceptualisation of history found in discussions of Western modernity and post-modernity, the term contemporaneity has been used in cultural theory, art theory and philosophy to discuss new ideas about the multiple, and often conflicting times, memories and histories of global, twenty-first century culture. ${ }^{18}$ Modernity was described as marked by a type of time that was one-dimensional, progressive and oriented towards the production of a shared future. Post-modernity, on the other hand was conceived as, among other things, the aftermath of this type of time. The term contemporaneity is a way of getting beyond a one-dimensional model of time, framed solely via the concept of progress and history, as moments with clear boundaries, bracketed of from one another. It instead encourages thinking about the present as a conjuncture of other, multiple and sometimes conflicting versions of time. ${ }^{19}$

\footnotetext{
${ }^{17}$ Rachel Wagner, "The Importance of Playing in Earnest," In Playing with Religion in Digital Games, eds. Heidi Campbell and Gregory Grieves, (Bloomington: Indiana University Press, 2014), pp. 192-213.

${ }^{18}$ See for instance Terry Smith, "Contemporary Art and Contemporaneity," Critical Inquiry 32:4 (2006): 681707 and Peter Osborne, Anywhere or Not at All: Philosophies of Contemporary Art (London and Brooklyn: Verso, 2013).

19 Juliane Rebentisch, "The Contemporaneity of Contemporary Art," New German Critique 42:1 (2015): 223237, pp. 233-234.
} 
Contemporaneity is not simply a way to conceptualise the coming together of individuals in time, but, as Peter

Osborne argues, it represents a way to conceive of the condition of global networks as a coming together of times:

we do not just live or exist together 'in time' with our contemporaries - as if time itself is indifferent to this existing together - but rather the present is increasingly characterized by a coming together of different but equally 'present' temporalities or 'times', a temporal unity in disjunction, or a disjunctive unity of present times [emphasis in original]. ${ }^{20}$

Contemporary art - in which I include the contemporary media arts such as game design - differentiates itself from modern art in that it expresses, engages with or otherwise reflects these conditions of the present. Modern art was an art for the future. 'Being modern means to live in a project, to practice a work in progress. Because of this permanent movement toward the future, modern art tends to overlook, to forget the present, to reduce it to a permanently self-effacing moment of transition from past to future'. ${ }^{21}$ The present for what we now call contemporary art, which is its proper subject, is not one step in the progression of modernity, promising a transition to a better, shared future, but rather a location where multi-temporalities and multiple competing histories are possible. In digitally mediated games, this not only happens via the game as text but it is also facilitated by a technical a priori that privileges discrete states and non-linearity. 'If modernity projects a present of permanent transition, forever reaching beyond itself, the contemporary fixes or enfolds such transitoriness within the duration of a conjuncture. ${ }^{22}$ This is the very experience of time captured by Huizinga at the beginning of this paper. Once play is 'over' (since it has played itself out in the present) it is simultaneously fixed and ready to be transmitted over much longer timescales as a tradition, ritual practices, or as a technique that endures.

We could say that the cultural techniques that define 'being contemporary' involve the fixing of an intense focus on the present, rather than a past or future. As Groys writes, 'being contemporary can be understood as being immediately present, as being here-and-now. In this sense, art seems to be truly contemporary if it is perceived as being authentic, as being able to capture and express the presence of the present in a way that is radically

\footnotetext{
${ }^{20}$ Osborne, Anywhere or Not at All (above, n. 34), p. 17.

${ }^{21}$ Boris Groys in Smith, "Introduction" (above, n. 3), p. 7.

22 Osborne, Anywhere or Not at All (above, n. 34), p. 24
} 
uncorrupted by past traditions or strategies aiming at success in the future. ${ }^{23}$ For Groys, the time of the present is manifest in the seemingly extended delay or usurpation of progress, in the hesitations and blockages that are produced by conflicting individualised times and that stop the transition to a shared future. In this sense, the game as a machine acts as just this blockage, which interrupts and organises flows. The game acts as a blockage to a shared future by functioning as a machine that introduces multiple, possible, time-based scenarios, which, as is seen in both The Outlands and Journey, focuses the attention of the player onto a carefully timed toand-fro of being-in-the-present. In the following two sections I illustrate this experience with a description of two quite different games that give form to the condition of contemporaneity and the prolonged periods of uncertainty and repetition described by Groys. This includes the cultural techniques associated with living within and manipulating programmatic time; the cultural techniques of preserving and accessing the memory of another; and the cultural techniques of locating versions of history through engagement rather than symbolic correspondence. These are techniques that can be seen to be common place in video games. The examples used are chosen because of the way they amplify these techniques and illustrate these often-latent ways of thinking about time.

\section{Time in games: Superhot and programmatic time}

The manipulation of time is a central feature of the indie First-Person Shooter (FPS) Superhot (Superhot Team 2016). At the start of the game the player is told 'time only moves when you move'. Through gameplay, it soon becomes clear that with each frame of movement the player makes, the enemy also makes a commensurate move. If the player does not move, the enemies do not move. Like in The Outlands, Superhot presents a controlled sense of time; the user has to learn to react and navigate the space based on the temporality of the system, which is different from familiar human experiences of time. Both these games act as an order making apparatus.

Superhot begins with a blank screen. A 'disk check' command line appears. The game then opens to a page resembling older text-based gaming that displays the anachronistic text: 'piOS, the operating system of the future'. Upon selecting the superhot.exe file, the game begins. In the initial levels, as is common practice in game design, the player learns the controls and as they move through the game, the difficulty of each level

\footnotetext{
${ }^{23}$ Boris Groys Comrades of Time. E-Flux 11 (2009). available at http://www.eflux.com/journal/11/61345/comrades-of-time/
} 
increases slightly. In these initial levels the player can therefore test out the best strategies of movement in the game, in a sense training for the levels to come and learning how to control time in the game.

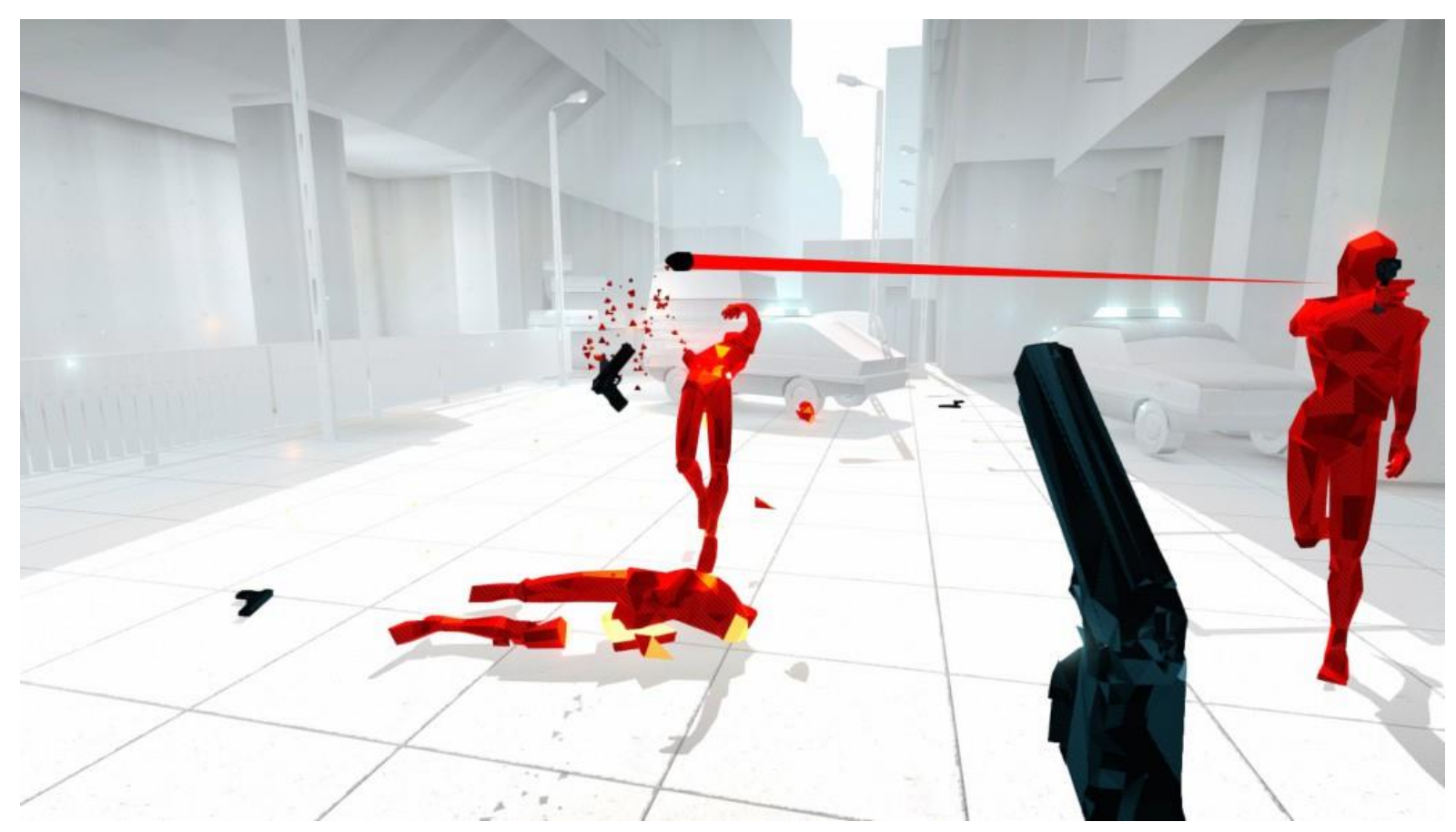

FIGURE 2

Superhot (Superhot Team, 2016)

As the game progresses, the player is asked to take on the role of a hacker - a figure usually associated with autonomy and the ability to create something new from within programmes. The conceit of Superhot is that the player-as-hacker has been sent a new game that they are trying out for the first time, testing it out to see what it can do. At moments, between standard game play, Superhot returns players to the emulated computer screen where they chat online with another player, asking about the game and discussing ways to unlock more levels. There is also a moment towards the start of the game where it appears that the player, as the hacker, can see themselves playing the game. There are cameras throughout each level of Superhot and there are moments where odd commands flash on the screen, appearing to come from an outside agency that has your gameplay under surveillance. At these and other moments, the game subverts the identity of the hacker as a figure with autonomy. At these points the game forefronts issues of surveillance and agency in digital culture. A large part of this manipulation of agency has to do with the way time is represented within the game. 


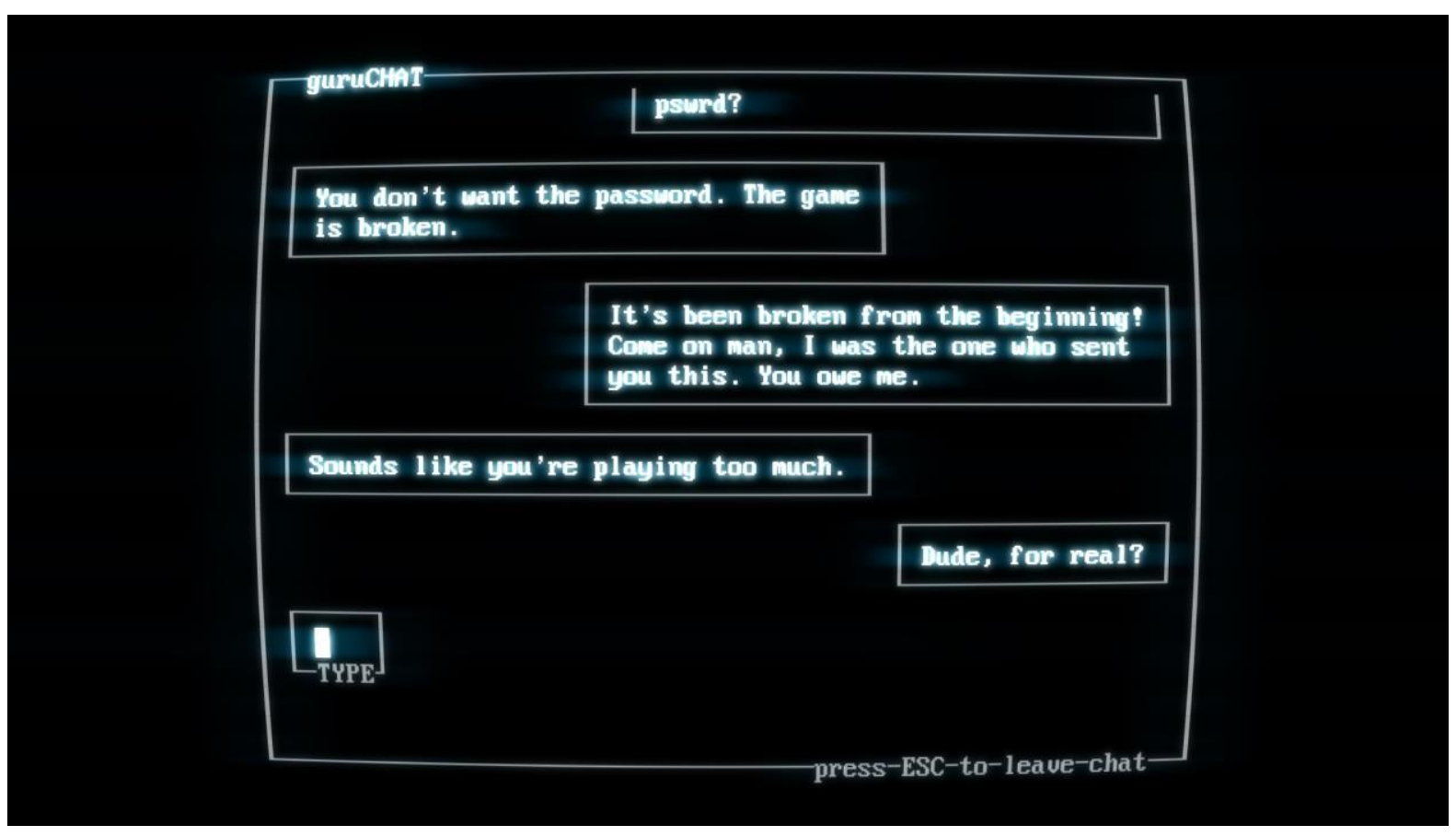

FIGURE 3

Chat screen in Superhot

Time in Superhot is made dysfunctional; it does not flow or proceed in an orderly manner but is rather organised based on the interaction of the player with the game. When I play Superhot it is not so much the slowness of time that is affective or disorientating but the pace at which something unexpected can happen: for instance, when someone comes at you from a blind spot, or when a bullet appears quickly out of nowhere. I have too much time and then, all of a sudden, not enough. While there is a perceived closeness with time, as the player seemingly controls the movements of objects in the world via their own movements around the game space, there is also a distancing from time, as it soon becomes apparent, that it is not the player that is controlling time but rather the game system that is controlling the player's movements - and therefore the type of time that passes as they are playing the game. This is most apparent when the player slows down time only to make a small movement that then causes a sudden onslaught of bullets. It is obvious at these moments that to succeed the player must submit explicitly to the parameters of the game that are outside of their control as they can only select from a restricted number of best possible moves amongst all that are available. The game at these moments mirrors what Jonathan Crary identifies as the need for users to 'invent a self-understanding that optimizes or facilitates their participation in digital milieus and speeds. ${ }^{24}$ Crary begins to argue that given digital economic realities, what he calls $24 / 7$ capitalism, individuals begin to seek to alter lived experience in a

\footnotetext{
${ }^{24}$ Jonathan Crary, 24/7: Late Capitalism and the Ends of Sleep (London: Verso, 2013), p. 100.
} 
delusional attempt to harmonise their own lives with that of machines. The user needs to learn to impersonate the computer, to think, as is the case in Superhot, along its timescales. Of course, this is not possible. But what this game offers is a construction of the 'fantasmatic compatibilities' ${ }^{25}$ between the player and the gaming system.

Superhot provides a context for play and a reflection on the experience of play that involves slowness and repetition. More than this though, Superhot expresses the time of the digital as involving multiple scales of temporality, both the very slow and the very fast at the same time; the player plays within a slowed down time but plays within a system that is predicated on very fast technical processes, which always outpace the player. Video games have always allowed players to control time. Players return repeatedly to saved positions, they die and then respawn, they can pause the game, they can return to a game they have not played for months or years and still be able to pick up where they left off. Superhot draw on this game mechanic and, because it so radically amplifies this characteristic of all video games, it becomes dysfunctional. What Superhot makes clear is that it is always the game, not the player that controls time. In the 'tutorial level' of Superhot, which comes not at the start but in the middle of the game, the player, now located in a cell, is instructed to keep moving, to walk and then to stand still. When they do this satisfactorily, the onscreen text rewards you with a 'GOOD'. At the end of the tutorial the message reads 'GOOD DOG' and then 'YOU ARE NOT IN CONTROL'. ${ }^{26}$ In this way it is evident that the player does not shape the game, but rather - in full accord with process philosophical descriptions from A.N. Whitehead to Deleuze - participates, or fulfils a condition, within the gaming system. ${ }^{27}$

The cultural techniques of play, much like the techniques of writing, film-making and photography, are a way of ordering events and generating concepts, which then represent the meaningfulness of these events. The key point here is that the process of playing generates these conditions for meaningfulness. As Macho has argued, cultural techniques are always older than the concepts that they generate. 'People wrote long before they conceptualised writing or alphabets; millennia passed before pictures and statues gave rise to the concept of the image. ${ }^{28}$ Play likewise gives rise to the concept of a game (as a programmed machine) and a player (as a

\footnotetext{
${ }^{25}$ Ibid.

${ }^{26}$ Conor McKeown, Videogame Ecologies: Interaction, Aesthetics, Affect. PhD Thesis, The University of Glasgow, 2017

${ }^{27}$ Barker, Time and the Digital (above, n. 4), pp. 117-118.

${ }^{28}$ Thomas Macho, "Second-Order Animals: Cultural Techniques of Identity and Identification." Theory, Culture and Society 30:6 (2013): 30-47, pp. 44-45.
} 
cultural identity). It is play itself that is primary to the game and to the subjectivity that emerges from its playing out. We can see an indication of this larger philosophical claim in Huizinga's work. He writes, once people started playing, soon structures and rules were invented to regulate play. 'Inside the play-ground an absolute and peculiar order reigns. Here we come across another, very positive feature of play: it creates order, is order. Into an imperfect world and into the confusion of life it brings a temporary, a limited perfection. Play demands order absolute and supreme. ${ }^{29}$ As the rules for the game were produced, the identity of the player was established as someone who might then be differentiated from those other individuals carrying out normal, everyday activities because of the way the game orders their activity. The identity of the player was dictated by the way the machine of the game interrupts their actions and insists on a to-and-fro of moves, becomes fixated on being and acting in the present. The identity of the player is constituted, at least from the perspective of the machine, as a series of inputs conditioned by the time-critical operation of the gaming system.

In this analysis of Superhot we can see that cultural techniques are never solely dependent on human actions. The game is not simply constituted by the actions of the player. Techniques such as gaming always presuppose technical objects capable of performing, facilitating and supporting the operations of a player. 'An abacus allows for different calculations than do ten fingers; a computer, in turn, allows for different calculations than does an abacus. ${ }^{30}$ In terms of play, the action of a player presupposes a gaming system, whether this is a computer, a chess board or a playground. These systems, as with the technical systems for calculating, all afford the user different possibilities for action. They insist on the user forming a relationship with the rhythmic and timecritical operations of the game system, as a state machine.

Playfulness in Superhot can be theorised as the production of a subject, as an articulation of the real, which is an outcome of a user's engagement within a gaming system. In a way that echoes my reading of Deleuze and Guattari's abstract machine, Huizinga writes that play is never radically subjective, but always involves a reliance on structured action. Play always involves move and counter move. The player has to either wait and see how other players or objects will respond to a move or, in the instance of games that require simultaneous movement by players, react to the outcome of moves in the next round. In Chess the player must react to the

\footnotetext{
${ }^{29}$ Huizinga, Homo Ludens Homo Ludens: A Study of the Play Element in Culture (London, Boston and Henley: Routledge and Kegan Paul, 1949), p. 10.

${ }^{30}$ Bernhard Siegert, Cultural Techniques: Grids, Filters, Doors and Other Articulations of the Real. (New York: Fordham University Press, 2015), p. 11.
} 
move of their opponent based on the way it effects and changes the game as a whole. In a video games such as Frozen Synapse (Mode 7 Games, 2011) players plan out moves in advance, which are then resolved simultaneously. To be successful, players must try and predict the moves of other players in advance. A player assuming they are playing rationally - must try and imagine the decisions that the other player will make in order to outflank them. In all these games there is a pattern of movement, a to-and-fro between the self and the other (whether this is a human other or a programmed object) that characterises the experience. "Instead of saying 'there is someone playing', it might be better to say 'there is playing going on. ${ }^{31}$ Because of this, play is able to give cultural form to the experience of being engaged in contact with the other, while held at arm's length from the other by the cybernetic system of the game. As Rodriguez writes,

this "waiting to see" indicates an essential feature about the activity of playing: that there is always something other, and so play is seldom radically subjective. The experience of the player is partly constituted by this moment of otherness. The player must respond to some event, in the context of a structured situation. Playing consists in a trans-individual process of action and reaction, which often takes on a to-and-fro quality reminiscent of dance. ${ }^{32}$

In Superhot the gaming system quite obviously reveals itself as a system for structuring the situation, the to-andfro of action, the contingent, in the game. Ultimately it produces a time that is linked to the movement of a player, yet it also makes it very obvious that it is the system, not the player, that is in charge of producing the game experience through its organisation of time. The 'waiting to see' of games, the anxious waiting for the other, the waiting for something to happen that the player can then respond to, constitutes an experience of otherness in playfulness. Play is never an experience that is produced by the player alone; it, as Rodriguez suggests, presupposes a to-and-fro with the other. Time in Superhot is programmed by a gaming system that carefully paces these moments of anxious waiting to see. While this is a feature possessed by most games - a waiting to see what the opponent does, waiting to see how the game system processes the player's actions or waiting for the next round in the case of games that require simultaneous moves - in Superhot the amplification and self-reflexive quality of this waiting allows the player to become conscious of the game and its rules as it is being played.

\footnotetext{
${ }^{31}$ Hector Rodriguez, "The Playful and the Serious: An approximation to Huizinga's Homo Ludens," Game Studies 6:1 (2006), available at http://gamestudies.org/0601/articles/rodriges

32 Ibid.
} 


\section{Time in games: Memory in That Dragon, Cancer}

While an analysis of the cultural techniques of play in Superhot can indicate how the apparent 'present tense' of contemporary subjectivity in digital culture could be rethought, in a media philosophical sense, as inputs conditioned by the time-critical operation of the gaming system, analysing the time-critical operation of play can also allow for a thinking through of the way users store and access memories in digital culture. This would involve thinking about the cultural techniques of play in digital culture as they relate to the way users access and inhabit the memory of another. In this section I explore the beautifully melancholic game That Dragon, Cancer (fig. 4) and show how it offers the player ways to occupy another's memory and 'play through', in a deeply affecting way, the trauma of losing a child to cancer. Games such as this do not simply offer the player a way of passing the time through play. Rather, they illustrate the play element of digital culture by offering a mode of being in multiple times simultaneously, with the player interacting in the time of hardware and software, regulated by the console's internal clock but also interacting out of this time in the diegetic world of the game, where players can apparently relive a past that was never theirs. ${ }^{33}$

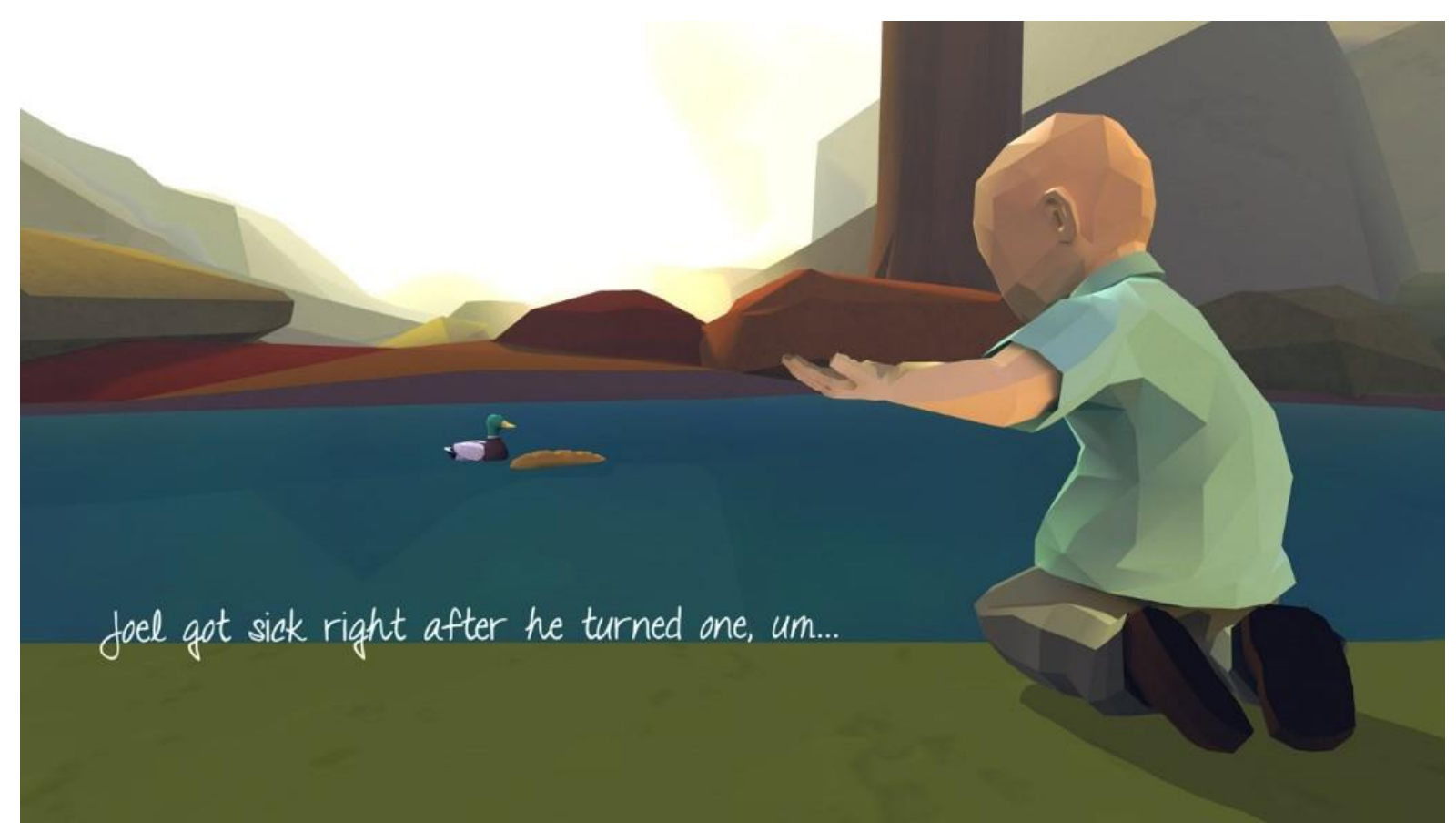

FIGURE 2

Still from That Dragon, Cancer Numinous Games 2016

\footnotetext{
${ }^{33}$ This is similar to the arguments put forward by Alison Landsberg in Prosthetic Memory: The Transformation of American Remembrance in the Age of Mass Culture, particularly her illustration of the emergence of a new type of personally felt public memory in popular culture.
} 
That Dragon, Cancer is a game designed by Ryan and Amy Green, and through 14 levels of game play represents the struggle of their son Joel, who, since his first birthday, battled aggressive brain cancers. The game opens with a simplified image of a child feeding ducks in a pond. The player hears conversations that are apparently between parents and a child, explaining why Joel can't speak like other children (a result of his treatment). From the beginning the player is allowed in to the intimate space of the family; he or she is a part of their intimate conversations and can play with Joel. The game, although moving through what could be considered levels, places emphasis not on obtaining points or achieving goals. There is, in effect, no real goal and no meaningful way to affect the outcome of the game. At the end of the game, the player may attempt to play a piano keyboard to unlock the game's conclusion. But these actions have no effect. The keys do not control anything. At the end of the game the player sees the message 'Thanks for Playing'. The entirety of the game could in fact be interpreted in light of this final scene and its final message to players. The game here reveals that it is not about progressing through a narrative, nor about the possibility of winning, but simply about play itself. It is about inhabiting a space of trauma, life in the hospital, life alongside a terminally ill child, and being able to play in these spaces. The game is about playing with Joel, inhabiting these moments that are both beautiful and tragic.

The dialogue of That Dragon, Cancer comes from transcripts, phone messages and home video recordings; things that have been recorded by other media technologies and which now support and replay the memory of moments from Joel's life. In one scene you can listen to a voicemail from Amy discussing Joel's treatment. In another you can explore the paintings produced by cancer sufferers, hanging on the hospital walls. Scenes like this give the player access to traces of the stored memory of Joel's life, recorded via cultural techniques of communication, memory and preservation. In another scene, the hospital space is filled with cards containing messages to children and adults that are battling cancer. In this card 'level' the player can open cards in Joel's hospital room, as his mother nurses him, rocks him and hums him to sleep. The game in this level therefore asks the player to read cards written by family members of cancer victims as if they were clues in a traditional adventure game. When I played this level, as I left Joel's room, having read every card, the entire hospital was revealed to be filled with cards. A player can read as many or as few cards as they chose, before completing the level, and exiting through the open hospital door. Yet in this context, when the player is involved in rehearsing this cultural technique of playful exploration (an experience familiar to many games) here the cards' emotional power disrupts the usually smooth sense of progress; instead there is an associated feeling of guilt, and the 
possibility of having missed something as well as an awareness of their own inability to exhaust fully the program of the game.

In the scene of the hospital the player is asked to operate amongst a collection of memory objects, and to therefore explore the collective trauma of a terminal childhood illness. In the next level the player occupies a room with two doctors, as well as Joel, Amy and Ryan. It is here that the player learn that Joel's chemotherapy treatment has failed. The player can choose to occupy Ryan, Amy's or the doctors' perspective, accompanied by a first-person voice-over describing their reaction. However, selecting a role cannot affect the outcome - or Joel's prognosis - but simply allows the player to explore the way the event might be experienced from different simulated perspectives. In every 'level' the player is reminded that they are not in control. In one level Joel floats, holding balloons. The player's task is to avoid the black cancer cells that will pop his balloons. But, no matter how skilled, eventually the player always fails. On March 132014 Joel died as a result of a tumour near his brain stem. The game ultimately reminds the player of their lack of agency and is a giving over to the time of the apparatus and the rituals associated with play.

In their description of contemporaneity - or the conditions for being contemporary - theorists such as Smith, Groys and Osborne seek to explore what happens after people have stopped believing in the models of history offered by the modernist project. They ask, if we have stopped believing in the progression of history, if we have stopped believing that we live progressively through eras that are directed towards ever increasing knowledge, what are the new conditions for being in time? In this tragic game, which continually repeats the memories of the near present, we can see the traumatic effects of this condition, not in terms of global politics but in terms of our most intimate relationships as children, siblings and parents. To be contemporary, art has only one option - to focus on the ontology of the present. In terms of That Dragon, Cancer this is a present that is thick with memories. By playing within the spaces of repeated trauma or with memory objects the player experiences a being-with, or a hesitating-with these memories of another. To be contemporary, art becomes anachronistic. The medium of computer gaming offers a type of time that allows for repetition, delay and limited interactivity which insists that the player become contemporary with the time of trauma. Within the era of the contemporary, the experience, or perception of time is not bound to the future or the past, but fixated on the present and the multiple, fragmented and anachronistic temporalities that are embedded in this experience of present-ness. 
In That Dragon, Cancer we can see a way of ordering time and documenting experiences that can be relived, in the sense of being played out, in the present. It re-presents a space, which feels both sacred and playful, where the gamer may 'play through' the memories of the other. That Dragon, Cancer is therefore played out in a 'staked out' space. 'A sacred space, a temporarily real world of its own, has been expressly hedged off for it. ${ }^{34}$ The time experienced within this space consists of multiple memories and the deep time of grief. The repetition and opportunity the game provides therefore sheds light, as Huizinga puts it, on the 'ordinary world. ${ }^{, 35}$ Playing That Dragon, Cancer offers an experience where the recent past is filtered by the apparatus of gaming in order to generate a 'real world' and a real time of its own. But it is also an experience where players can 'play through' grief. That Dragon, Cancer provides players with a game space that allows them to repeatedly interact with another's memory, to explore the mediations of memory, via phone messages, paintings, recordings and cards. It represents or reveals an experience of present-ness that is thick with multiple memories and multiple levels of mediation.

In previous literature on games and time, the capacity for the logic of digital software to reduce the complexity of events has been suggested. Alexander Galloway has written about the organisation of historical time in games such as Sid Meier's Civilization series, which present a certain reification of history. Galloway writes, the game Civilisation 'transposes the many-layered quality of social life to an inflexible, reductive algorithm for 'civilization'. ${ }^{36}$ Or, as Jodi Byrd argues mediations of history in games like this often follow a 'single-minded trajectory of forward momentum', where even in vast open world games, complexity is mitigated by the funnelling of "storyline advancement into stages and enemy confrontations that get progressively more and more difficult the deeper and further a player proceeds. ${ }^{37}$ The game becomes, as both Galloway and Byrd argue, a procedural media system that captures and orders history. While I agree with Galloway and Byrd's assessments of the way mainstream historical games have tended to reduce complexity due to interaction design, this is only part of the story. As is seen above, there also exists opportunities for games, and digital media in general, to

\footnotetext{
${ }^{34}$ Huizinga, Homo Ludens (above, n. 31), p. 14

35 lbid.

${ }^{36}$ Alexander Galloway, “Playing the Code; Allegories of Control in Civilisation.” Radical Philosophy 128 (2004), available at https://www.radicalphilosophyarchive.com/article/playing-the-code

37 Jodi A. Byrd, 'Do they not have rational souls?': consolidation and sovereignty in digital new worlds, Settler Colonial Studies, 6:4 (2016), available at https://www.tandfonline.com/doi/full/10.1080/2201473X.2015.1090635?src=recsys
} 
produce new, more complex versions of temporal events and offer new ways to live with and through these events.

Games are special types of cultural techniques in that through their operation as machines, they provide opportunities for the representability of time. Contemporary techniques of play can be seen as time-critical in the technical sense that games, particularly digitally mediated games, are based on notions of timeliness, speed and the ability to process events in time. Games are also time-critical in an epistemological sense: they allow a critical engagement with time by providing the player with a way to reproduce, measure, and control time. In this sense, games, like all cultural techniques, provide a context for humans to understand themselves and the culture from which they emerge. Games are special in that they allow for a particular engagement with digital temporality. Games are thus time-critical processes in two senses: they not only operate in time but are themselves, through their technical operation, productive of ways to conceptualise the time of the digital.

Games such as That Dragon, Cancer provide a space where the interaction between a player and a system becomes similar to ritual, in that both express a desire for communication with the other. In games like this, players continue to engage with other identities in a way that is more than symbolic correspondence, more than just a 'sham reality. ${ }^{38}$ To play a game, an individual needs to become a player. To avoid being a spoil-sport, the player then needs to become a character. These actions, like in the rites that Huizinga describes, bring about an order of things.

\section{Conclusion}

Huizinga writes that play, after it is over, endures as a product of the mind, as a memory or as a tradition. 'It is transmitted, it becomes tradition'. And with this tradition the game is restored in the present. Transmitted throughout contemporary culture, particularly but not exclusively in the digital environments of culture, these traditions, rituals and ways of being can be repeated at any time, 'whether it be a child's toy, or a game of chess or at fixed intervals, like a mystery. ${ }^{39}$ In nearly all higher forms of play the elements of repetition and alternation (as in the refrain), are like the warp and woof of a fabric. ${ }^{40}$ This passage is commonly read as simply stating that the game, whether it be a schoolyard game of tag or a high stakes game of poker itself is each

\footnotetext{
38 Ibid.

39 Ibid., 10

40 Ibid.
} 
time that it is played repeated but also made different. But we can also read in Huizinga's text that the games themselves are ways of retrieving past ways of being, but also ways of escaping these ways of being. Huizinga gives us the term 'refrain' in brackets, which he seems to use in a way that pre-supposes the terms reformulation in the work of Deleuze and Guattari, as mentioned at the beginning of this paper. The refrain acts as a moment of emergence out of chaos, it is a rhythm that emerges, it creates stability, temporary moments and temporary relations between elements. The refrain is always played. It is always a game. In the Deleuze and Guattarian sense, the game becomes the milieu in which time is given its rhythm. It is this refrain which we can see when we analyse playfulness as a cultural technique. It is this refrain that produces the identity of the player. It is this refrain which signifies the repetition of the game but also the difference that it expresses. It is the refrain that sweeps digital culture along.

In describing the playing of the refrain, in this paper I have used the term cultural technique. As has been outlined above, cultural techniques refer to the strategies and technical functions for dealing with symbolic worlds, such as reading, writing, listening, viewing, counting and visualizing. Games ask players to participate within a program in a similar way that writing asks writers to participate within a system of grammatical rules and technical media, such as word processors, typewriters, ink, and pens as well as institutional systems including libraries and the publishing industry. In games, as in forms of experimental writing, players are asked to explore the limits of these programs, to attempt to, in Vilém Flusser's language, discover them and exhaust them. ${ }^{41}$ The practice of play amounts to the testing out of a system, seeing what it can do, exploring the new worlds that it can create, with an orientation on the struggles, or the to-and-fros in the present. Now I can conclude that with this approach we can see more about time and the digital than was previously possible. It is not simply that the time of the digital should be described as constantly accelerating, nor as malleable, nor as predicated on ideas of storage, but that the time of the digital is produced via the figure of the player who is made manifest by, and is able to act within, these systems. This approach does not merely look to the technical conditions for temporality, following Ernst or Friedrich Kittler, nor does it look solely as the subjective experiences of time, following Sharma or Judy Wajcman. Instead it looks to the sharing of agency between users and systems as a set of cultural techniques that may account for the production of digital temporality and its significance for the becoming of the digital subject.

\footnotetext{
${ }^{41}$ Vilém Flusser, Post-History. (Minneapolis: Univocal [1983]2013), pp. 19-26
} 
In this paper I set out the time-critical cultural techniques of play by using examples that amplify - and thus allow us to see more easily - common gaming tropes and how they facilitate, determine and provoke the contemporary. Games like Haines and Hinterding's The Outlands re-appropriate common gaming practices to make these work against themselves. The present moment in The Outlands dilates and the players simply drift among an archive of the leftovers of chronological action. But there are also other games that present time as multi-temporal, involving multiple times experienced in the present. Indie games such as That Dragon, Cancer draw on the way in which games allow players to relive memories and amplifies the cultural technique of reliving histories and memories through play, making play dysfunctional and making the game emotionally difficult to play through. Games such as Superhot scale-up the game mechanics that organise temporality, in terms of reloading, respawning and saving, confirming that it is the game, not the player, that produces the time of play. In all these games the game mechanics and the cultural techniques associated with play organise temporality and become productive of a present that can be replayed and repeated. If Western modernity was marked by the ideology of progress and an attention to a past and future over the present, then the contemporary, as expressed in these games, is marked by a playing out in the present of the refrain. Media aesthetics, such as those produced by the art games and indie games mentioned in this paper, take time and its mediation as their proper form. Their contemporaneity comes from their focus on the complex of times represented in the present through play and the way that this representability allows for a critical reflection on how history, memory and performance is being mediated and produced as a disjunctive unity in the present.

Seeing play as a time-critical cultural technique allows us to describe new things about digital culture. We are able to conclude that play as a cultural technique - one that has become so dominant in digital culture that it is impossible to ignore - signals a shift from the $20^{\text {th }}$ century version of time media offered to us by Doane. We are also able to see that, unlike concepts of digital accelerationism or non-anthropocentric time, the actions of a human user and the networks of human and technological agency that constructs the identity of a player becomes crucial in the understanding of digital culture. Individuals are not simply victim to the ever-increasing speed and storage capacity of digital computers. Instead we become complicit in the construction of time in digital culture by taking on the identity of a player. This can only be seen by taking the cultural technique approach, which, via its reformulation of media archaeology, highlights the way identities and experiences are constructed through human machine interactions. Finally, this essay has allowed us to re-evaluate the way time is represented in games, by framing its enquiry with the theoretical framework of contemporaneity. Games 
produce multiple and often conflicting senses of time by establishing a to-and-fro with the other, conceptualised here as a computer system. Rather than focussing purely on the representation of time via game mechanics or content, the paper has offered a way to see games as both reflecting and supporting the conditions of contemporaneity through their capacity to allow players to engage with multiple versions of temporality, history and memories.

\section{Bibliography}

Barker, Timothy. Time and the Digital: Connecting Aesthetics, Technology and a Process Philosophy of Time. New Hampshire: Dartmouth College Press, 2012.

Byrd, Jodi A. "'Do they not have rational souls?': consolidation and sovereignty in digital new worlds." Settler Colonial Studies, 6:4 (2016), available at https://www.tandfonline.com/doi/full/10.1080/2201473X.2015.1090635?src=recsys Costikyan, Greg. Uncertaintity in Games. Cambridge, MA: The MIT Press, 2015. Crary, Jonathan. 24/7: Late Capitalism and the Ends of Sleep. London: Verso, 2013. Crary, Jonathan. Techniques of the Observer: On Vision and Modernity in the Nineteenth Century. Cambridge, MA: The MIT Press, 1992.

Deleuze, Gilles and Guattari, Felix. A Thousand Plateaus: Capitalism and Schizophrenia. London and New York: Continuum, [1980]1987.

Deleuze, Gilles, Guattari, Felix and Stivale, Charles. Concrete Rules and Abstract Machines. SubStance, 13:3/4 (1984): 7-19.

Doane, Mary Ann. The Emergence of Cinematic Time. Cambridge, MA: Harvard University Press, 2002.

Ernst, Wolfgang. Chronopoetics: The Temporal Being and Operativity of Technological Media. Lanham: Rowman and Littlefield, [2012]2016.

Flusser, Vilém. Post-History. Minneapolis: Univocal [1983]2013.

Galloway, Alexander. "Playing the Code; Allegories of Control in Civilisation." Radical Philosophy 128 (2004), available at https://www.radicalphilosophyarchive.com/article/playing-the-code 
Groys, Boris. “Comrades of Time." E-Flux 11 (2009), available at http://www.e-

flux.com/journal/11/61345/comrades-of-time/

Groys, Boris. In the Flow. London and New York: Verso, 2016.

Hanson, Christopher. "Repetition." In Routledge Companion to Video Game Studies, edited by Mark J.P. Wolf and Bernard Perron, 204-210, New York and Oxon: Routledge, 2014.

Hanson, Christopher. Game Time: Understanding Temporality in Video Games. Bloomington: Indiana University Press, 2018.

Huizinga, Johan. Homo Ludens Homo Ludens: A Study of the Play Element in Culture. London, Boston and Henley: Routledge and Kegan Paul, 1949.

Juul, Jesper. Half-Real: Video Games between Real Rules and Fictional Games. Cambridge, MA: The MIT Press, 2005.

Landsberg, Alison. Prosthetic Memory: The Transformation of American Remembrance in the Age of Mass Culture. New York: Columbia University Press, 2004.

Macho, Thomas. "Second-Order Animals: Cultural Techniques of Identity and Identification." Theory, Culture and Society 30:6 (2013): 30-47

McKeown, Conor. Videogame Ecologies: Interaction, Aesthetics, Affect. PhD Thesis, The University of Glasgow, 2017.

Osborne, Peter. Anywhere or Not at All: Philosophies of Contemporary Art. London and Brooklyn: Verso, 2013.

Paton, Justin. "Artists, David Haines and Joyce Hinterding on their work 'The Outlands.'” Unguided Tours, Art Gallery of New South Wales, 2011, available at https://www.youtube.com/watch?v=YdstMcTGijE Rebentisch, Juliane. "The Contemporaneity of Contemporary Art," New German Critique 42:1 (2015): 223-237

Rodriguez, Hector. "The Playful and the Serious: An approximation to Huizinga's Homo Ludens," Game Studies 6:1 (2006), available at http://gamestudies.org/0601/articles/rodriges 
Sharma, Sarah. In the Meantime: Temporality and Cultural Politics. Durham and London: Duke University Press.

Sicart, Miguel. Play Matters. Cambridge, MA: The MIT Press, 2014.

Siegert, Bernhard. Cultural Techniques: Grids, Filters, Doors and Other Articulations of the Real. New York: Fordham University Press, 2015.

Smith, Terry. "Contemporary Art and Contemporaneity," Critical Inquiry 32:4 (2006): 681-707.

Smith, Terry. "Introduction: The Contemporary Question." In Antomonies of Art and Culture, edited by Terry Smith, Okwui Enwezor, and Nancy Condee, 1-19, Durham and London: Duke University Press, 2008.

Smith, Terry. What is Contemporary Art. Chicago: The University of Chicago Press, 2009.

Wagner, Rachel. "The Importance of Playing in Earnest," In Playing with Religion in Digital Games, edited by Heidi Campbell and Gregory Grieves, 192-213, Bloomington: Indiana University Press, 2014.

Wolf, Mark J. P. "Time in the Video Game." In The Medium of the Video Game, edited by Mark J. P. Wolf, 77-91, Austin, Texas: University of Texas Press, 2001. 